\title{
Fatty acids composition of erythrocytes in arterial hypertension associated with dyslipidemia
}

\author{
Tatyana P. Novgorodtseva, Yulia K. Karaman, Tatyana A. Gvozdenko, Marina V. Antonyuk, \\ Vera V. Knyshova
}

Vladivostok Branch of the Far Eastern Center of Physiology and Pathology of Respiration, SB RAMN, Institute of Medical Climatology and Rehabilitative Treatment, Vladivostok, Russia; karaman@inbox.ru

Received 20 February 2013; revised 25 March 2013; accepted 3 April 2013

Copyright (C) 2013 Tatyana P. Novgorodtseva et al. This is an open access article distributed under the Creative Commons Attribution License, which permits unrestricted use, distribution, and reproduction in any medium, provided the original work is properly cited.

\begin{abstract}
Studied the fatty acid (FA) composition of erythrocyte membranes in patients with arterial hypertension associated with dyslipidemia. The fatty acid composition of erythrocyte membranes was studied by gaz chromatography. In all hypertensive patients are disturbed lipid FA composition of erythrocytes: increase in saturated fatty acids $(15: 0,16: 0)$, monoenic fatty acids $(18: 1 n 9,18: 1 n 7)$, polyunsaturated fatty acids (PUFA) family $n 6$ (20:4n6), decrease in polyunsaturated fatty acids family $n 3: 22: 5 n 3,22: 6 n 3$, the total value of $n 3$ PUFA. Cells endogenous deficiency of n3 PUFA leads to the changes of the plasmatic membranes physicochemical properties, activation of eicosanoids synthesis with proinflammatory and vasoconstriction activity, the formation of the systemic inflammatory syndrome and conditions for the atherogenesis. Thus, structural and functional changes in erythrocyte membranes in hypertension developed as a part of the common systemic disorder of lipid metabolism.
\end{abstract}

Keywords: Fatty Acids; Arterial Hypertension; Dyslipidemia

\section{BACKGROUND}

Modification of fatty acids composition of the lipid matrix of cell membrane has an important role in arterial hypertension $(\mathrm{AH})$ pathogenesis. It's known that changes of the fatty acids (FA) composition, decreasing on quantity of essential polyunsaturated fatty acids (PUFA) may result in membrane microviscosity increasing, proinflammatory eicosanoids synthesis activation and increasing the smooth muscle cells in artery walls sensitivity to the influence of vasoconstrictors [1]. Cytosol hyperna- tremia and hypercalcemia developed in FA forming new ion channels of conductions assist to the functional disturbances of friable connective tissue, collagen and elastin increasing both synthesis and secretion. It probably leads to the thickening and decreasing of arteries walls flexibility [2]. Another negative side of depletion of the pool of physiologically important PUFAs in the cell membranes is a dysfunction of the synthesis of biologically active metabolites-oxylipins (eicosanoids: prostaglandins, leukotrienes, thromboxanes), which are the key regulators of the function of endothelium and thrombocytes [3, 4]. In most cases, the primary precursor of eicosanoids is arachidonic acid, its oxylipines have a higher biological activity than that of eicosanoids formed from dihomo$\gamma$-linolenic or eicosapentaenoic acids. Consequently, the contribution of arachidonic acid metabolism products and violation of their synthesis in the pathogenesis of many diseases is obvious and significant [4].

Researches devoted to the detailed study of the modification of FA in erythrocyte lipids in arterial hypertension don't create a general image of typical changes of FA composition in this category of patients which connected to the variety of associated disorders (obesity, resistance to the insulin, diabetes mellitus).

Arterial hypertension and dyslipidemia (DLP) - most important and commonly present risk factors [5-9], are with a prevalence of $50 \%-80 \%$ [10-13] according to the different authors. Among untreated patients with $\mathrm{AH}$ the frequency of DLP is $40 \%$, on the other hand almost one half of patients with increased level of total cholesterol (TC) has systolic and diastolic hypertension [14-17]. The confirmation of the adverse prognostic significance of hypercholesterolemia was obtained from results of the multicenter studies such as MRFIT (Multiple Risk Factor Intervention Trial) and the Seven Countries Study. According to these studies the growth of absolute and relative characteristics of mortality from cardiovascular dis- 
ease in direct dependence of the TC level [18-21] were demonstrated on large populations. That's why the great interest is that immersed studying of changing of the spectrum of FA in erythrocyte lipids in patients with arterial hypertension associated with dyslipidemia.

The aim of the work was to study the fatty acid composition of erythrocyte membranes in patients with arterial hypertension associated with dyslipidemia.

\section{MATERIALS AND METHODS}

The research was performed according to the principles of the Helsinki Declaration (2000), with 18 patients with diagnosed AH 1 - 2 stage, 10 male and 8 female (average age - $49.21 \pm 1.7$ ). The control group consisted of 11 almost healthy persons. The criteria for the inclusion into the study was diagnosed AH 1 - 2 stage. During diagnosis of $\mathrm{AH}$ practical recommendations of the European Society of Cardiology (ESC) and European Society of Hypertension (ESH) [22] were used. The criteria for exclusion were AH with 3 stages, secondary hypertension, associated with the pathology of the urinary system (urolithiasis, acute and chronic pyelonephritis, polycystic kidney disease), endocrine system (diabetes, hyperthyroidism, Cushing disease), as well as concomitant diseases of the cardiovascular system (coronary heart disease, stroke, myocardial infarction, cardiac arrhythmias).

The serum lipid spectrum was studied by the content of cholesterol, triglycerides (TG), high density lipoprotein cholesterol (HDL) in serum with biochemical analyzer Photometer FM 750 (Germany), and using sets of firm "Olvex" (Russia). Results were expressed in $\mathrm{mmol} /$ liter. The concentration of low density lipoproteins cholesterol (LDL) and very low (VLDL) density were calculated by the formula: $\mathrm{LDL}=$ total cholesterol $-(\mathrm{HDL}$ $+\mathrm{VLDL}), \mathrm{VLDL}=\mathrm{TG} / 2.2$, the results were expressed in $\mathrm{mmol} /$ liter. Atherogenicity index (AI) was calculated by the formula: $\mathrm{AI}=(\mathrm{TC}-\mathrm{HDL}) / \mathrm{HDL}$ [23]. The criteria for dyslipidemia were levels of total cholesterol (TC) > $5.0 \mathrm{mmol} / \mathrm{l}$, LDL cholesterol (LDL) > $3.0 \mathrm{mmol} / \mathrm{l}$, triglycerides $(\mathrm{TG})>1.77 \mathrm{mmol} / \mathrm{l}$, high density lipoprotein cholesterol $(\mathrm{CH} \mathrm{HDL})<1.0 \mathrm{mmol} / \mathrm{l}$, atherogenic index $(\mathrm{AI})>3.5$ a.u. [22].

The extraction of lipids from erythrocytes was performed by a modified method of Bligh and Dyer [24]. Gas-liquid chromatography of FA methyl ethers was performed on gas-liquid chromatography "Shimadzu-9A" (Japan) with a flame ionization detector. Methyl ethers of erythrocytes FA lipids were obtained by the method of Carreau and Dyubak [25] and purified by thin-layer chromatography. FA methyl ethers were analyzed by capillary columns. The Chromaton N-AW-DMCS 0.100 - 0.125 was used as carrier, 5\% Silar-5 CP, FFAP-as the liquid phase. The evaporation temperature was $245^{\circ} \mathrm{C}$.
The separation temperature was $210^{\circ} \mathrm{C}$. Helium was the gas-carrier with linear velocity $-20 \mathrm{~cm} / \mathrm{sec}$. The identification was performed using standard mixtures of FA and the values of the equivalent chain length $[26,27]$. Quantitative calculations were performed using the standard software of data processing systems ChromatopakCR 3A. Results were expressed in relative $\%$ of total FA. Unsaturation index (UsI) was calculated as the sum of the products of double bonds in each of the FA with its relative percentage.

Statistical data processing was performed using the methods of descriptive statistics: the arithmetic mean, the standard error of the arithmetic mean $(\mathrm{M} \pm \mathrm{m})$, the criteria for significant differences (t) Student [28].

\section{RESULTS}

Table 1 demonstrates the lipidogramm of the observed persons. The level of serum lipids in patients with $\mathrm{AH}$ has an increased concentration of total cholesterol, TG, LDL, VLDL, and IA, associated with the reduced level of HDL (Table 1).

The quantitative composition of the erythrocyte lipids FA in patients with AH presented with saturated, polyunsaturated fatty acids with carbon chain lengths from C12 to C22 (Table 2). The table doesn't contain some minor components of the FA which content does not exceed $0.1 \%$. As follows from Table 2, the FA composition in patients with AH and DLP demonstrated increased proportion of saturated and monoenic FA and reducing of polyenic FA. Most pronounced changes in the quantitative amount of saturated FA were established. An accumulation of 15:0 and 16:0 were revealed. Patients with AH associated with dyslipidemia have a high content of oleic acid (18:1n9) and Mead acid (20:3n9). Such changes in monoenic acids composition make the membrane more susceptible to oxidation while oleic acid, being active endogenous invader of the active oxygen forms, becomes a source of cytotoxic products of lipid peroxidation, initiates the processes of membrane destruction [1].

Changes in PUFA composition are more pronounced, especially with acids $n 3$ structure. PUFA family $n 3$ deficiency was confirmed with significant decrease of the proportion of docosapentaenoic (22:5n3) and docosahexaenoic PUFA (22:6n3). There was a reduction of the total value of n3 PUFA in patients with DLP. A distinctive parameter of patients with AH associated with DLP was rising of forerunner of eicosanoids with vasoconstrictor effects-arachidonic acid (20:4n6) to $26 \%$. This is a sign of polyunsaturated acids $n 3$ lack. The imbalance in the composition of PUFA n3 and n6 is reflected in the decreasing ratio $n 3 / n 6$. The patients have the accumulation of saturated and polyunsaturated n6 FA with deficit 
Table 1. Clinical and biochemical characteristics of patients with arterial hypertension, $\mathrm{M} \pm \mathrm{m}$.

\begin{tabular}{ccc}
\hline Parameters & Control group, $\mathrm{n}=11$ & Patients with AH + DLP, $\mathrm{n}=18$ \\
\hline Systolic arterial pressure, $\mathrm{mmHg}$. & $105 \pm 2$ & ${ }^{* * *} 141 \pm 1$ \\
Diastolic arterial pressure, $\mathrm{mmHg}$ & $65 \pm 2$ & ${ }^{* * *} 58 \pm 1$ \\
TC, $\mathrm{mmol} / \mathrm{l}$ & $4.44 \pm 0.210 .13$ \\
TG, $\mathrm{mmol} / \mathrm{l}$ & $0.68 \pm 0.07$ & ${ }^{* * *} 1.79 \pm 0.14$ \\
HDL, $\mathrm{mmol} / 1$ & $1.41 \pm 0.11$ & ${ }^{* * *} 0.97 \pm 0.05$ \\
LDL, $\mathrm{mmol} / 1$ & $2.72 \pm 0.22$ & ${ }^{* * *} 4.00 \pm 0.06$ \\
VLDL, $\mathrm{mmol} / 1$ & $0.31 \pm 0.03$ & ${ }^{* * *} 0.65 \pm 0.01$ \\
AI, a.u. & $2.27 \pm 0.05$ & ${ }^{* * *} 4.35 \pm 0.09$ \\
\hline
\end{tabular}

Note: tabl. 1, $2\left({ }^{*}\right)$ - statistically significant differences linked to the control group: ${ }^{*} \mathrm{p}<0.05 ;{ }^{* *} \mathrm{p}<0.01 ;{ }^{* * *} \mathrm{p}<0.001$.

Table 2. The content of FA in erythrocyte lipids in patients with AH, \% of total FA M $\pm \mathrm{m}$.

\begin{tabular}{|c|c|c|}
\hline Fatty acids & Control group, $\mathrm{n}=11$ & Patients with $\mathrm{AH}+\mathrm{DLP}, \mathrm{n}=18$ \\
\hline $14: 0$ & $0.65 \pm 0.04$ & ${ }^{* * *} 0.41 \pm 0.04$ \\
\hline $15: 0$ & $0.28 \pm 0.02$ & ${ }^{*} 0.41 \pm 0.05$ \\
\hline $16: 0$ & $23.37 \pm 0.32$ & ${ }^{* * *} 25.90 \pm 0.42$ \\
\hline $16: 1 \mathrm{n} 7$ & $0.80 \pm 0.03$ & $0.85 \pm 0.09$ \\
\hline $17: 0$ & $0.45 \pm 0.04$ & $0.42 \pm 0.01$ \\
\hline 18:0 & $17.23 \pm 0.29$ & $17.03 \pm 0.39$ \\
\hline $18: \ln 9$ & $13.25 \pm 0.55$ & ${ }^{* *} 15.02 \pm 0.32$ \\
\hline $18: \ln 7$ & $1.38 \pm 0.01$ & ${ }^{* *} 1.60 \pm 0.06$ \\
\hline $18: 2 \mathrm{n} 6$ & $13.74 \pm 0.53$ & $14.5 \pm 0.2$ \\
\hline $20: 0$ & $0.18 \pm 0.02$ & \\
\hline $20: 3 n 9$ & $0.48 \pm 0.05$ & ${ }^{* * *} 0.88 \pm 0.18$ \\
\hline $20: 4 n 6$ & $11.13 \pm 0.24$ & ${ }^{* * *} 13.18 \pm 0.18$ \\
\hline $20: 5 n 3$ & $1.08 \pm 0.11$ & $1.32 \pm 0.10$ \\
\hline $22: 4 n 6$ & $2.15 \pm 0.11$ & $1.89 \pm 0.13$ \\
\hline $22: 5 n 3$ & $2.42 \pm 0.16$ & ${ }^{* *} 1.81 \pm 0.08$ \\
\hline $22: 6 n 3$ & $5.8 \pm 0.3$ & ${ }^{* *} 4.18 \pm 0.40$ \\
\hline Sum $20-22 n 6$ & $16.35 \pm 0.52$ & ${ }^{* *} 14.38 \pm 0.41$ \\
\hline Sum $20-22 n 3$ & $9.2 \pm 0.3$ & ${ }^{*} 7.70 \pm 0.55$ \\
\hline $20-22 n 3 / 20-22 n 6$ & $0.58 \pm 0.03$ & $00.50 \pm 0.03$ \\
\hline Sum n6 & $30.1 \pm 0.6$ & $30.2 \pm 0.4$ \\
\hline Sum n3 & $9.98 \pm 0.78$ & ${ }^{*} 7.5 \pm 0.7$ \\
\hline $\mathrm{n} 3 / \mathrm{n} 6$ & $0.31 \pm 0.01$ & ${ }^{*} 0.26 \pm 0.02$ \\
\hline $22: 6 n 3 / 22: 5 n 3$ & $2.4 \pm 0.1$ & $2.26 \pm 0.15$ \\
\hline $20: 4 n 6 / 22: 6 n 3$ & $2.11 \pm 0.12$ & ${ }^{*} 2.53 \pm 0.13$ \\
\hline $20: 4 n 6 / 20: 3 n 6$ & $10.41 \pm 0.40$ & ${ }^{* * *} 8.54 \pm 0.31$ \\
\hline $20: 4 n 6 / 20: 5 n 3$ & $13.01 \pm 0.99$ & ${ }^{* * *} 8.01 \pm 0.42$ \\
\hline Unsaturation index & $155.98 \pm 1.33$ & $157.9 \pm 1.9$ \\
\hline
\end{tabular}

Note: tabl. $\left({ }^{*}\right)$ - statistically significant differences linked to the control group: ${ }^{*} \mathrm{p}<0.05 ;{ }^{* *} \mathrm{p}<0.01 ;{ }^{* * *} \mathrm{p}<0.001$.

of PUFA n3 in the cytomembrane which indicates on the decreasing of the fluidity of cell lipid bilayer, an activity of membrane bound enzymes and inhibition of binding the ligands with the receptor $[1,3,29,30]$. The change in the fatty acid composition in cell membranes, mainly the trend to lowering of the amount of the essential PUFA of phospholipids leads to a fall of the negative charge in the cell membrane, to increased membrane viscosity, activation of the synthesis of proinflammatory and vasoconstrictory eicosanoids, and to increased sensitivity of smooth muscle cells of artery walls to the action of vasoconstrictors $[25,26]$. These disorders are the major patho- genic factors in the development of cardiovascular diseases (hypertension, brain stroke, myocardial infarction). The reduction revealed in the concentration of arachidonic acid in the red blood cells indicates a disturbance of the eicosanoid cycle and an increased synthesis of oxylipins with expressed vasoconstriction (thromboxan A2) and anti-inflammatory (leukotrien B4) properties [30].

In respect that one of the reasons for modification of the FA is a disturbance of its metabolism; their rates of the transformations were analyzed. The analysis of parameters of the FA metabolic enzymes activity revealed the reduction of the ratio $20: 4 \mathrm{n} 6 / 20: 3 \mathrm{n} 6$, which indicat- 
ing the inhibition of eicosatrienoic acid metabolism. Discovered changes in the ratio $20: 4 n 6 / 20: 5 n 3$ and 20:4n6/ 22:6n3 involve an imbalance in eicosanoids cycle in the direction of increasing the oksilipins synthesis with marked vasoconstrictor (thromboxane A2) and proinflammatory (leukotriene B4) properties [1,3].

The results indicate a disturbance of the FA erythrocytes lipids in patients with $\mathrm{AH}$ and hyperlipidemia. It was shown that patients with $\mathrm{AH}$ associated with hypercholesterolemia and hypertriglyceridemia revealed a deeper restructuring of the erythrocytes membrane lipid matrix. The increased proportion of the pentadekanoic, palmitic and arachidonic acid were demonstrated. A distinctive feature of the modification of erythrocytes lipids FA in patients with AH associated with DLP was deficiency of PUFA n3. The observed prevalence of saturated FA proportion in the erythrocytes with simultaneous lack of polyunsaturated acids may be the evidence of transport pathology with a predominance of cells passive FA absorption. The integral parameters of the cells impaired absorption both of saturated FA and PUFA are low levels of HDL and high levels of TG and cholesterol in the blood serum [1-3]. Cells endogenous deficiency of $n 3$ PUFA leads to the changes of the plasmatic membranes physicochemical properties, activation of eicosanoids synthesis with proinflammatory and vasoconstriction activity, the formation of systemic inflammatory syndrome and conditions for the atherogenesis [1].

Thus, structural and functional changes in erythrocyte membranes in hypertension developed as a part of the common systemic disorders of lipid metabolism. Defects of receptormediated mechanism for the FA capture induce the formation of $\mathrm{AH}$. The increase in thedisorganization of the lipid components of the cell membrane causes the development of hyperlipidemia and progression of hypertension. These findings clearly demonstrate the important role of fatty acids in the pathogenesis of cardiovascular diseases.

\section{REFERENCES}

[1] Endakova, E.A., Novgorodtseva, T.P. and Svetashev, V.I. (2002) Modification of blood fatty acids composition in case of cardiovascular diseases. Vladivostok, 296.

[2] Titov, V.N. (2002) Atherosclerosis as a pathology polien fatty acids. Biological bases pathogenesis, diagnostics, preventive and treatment of atherosclerosis. M: Altus, 750.

[3] Titov, V.N. (1998) Violation of transport in cells of saturated fatty acids in the pathogenesis of essential hypertension. Vopr Med Khim., 44, 317-330.

[4] Novgorodtseva, T.P., Karaman, Y.K., Zhukova, N.V., Lobanova, E.G., Antonyuk, M.V. and Kantur, T.A. (2011) Composition of fatty acids in plasma and erythrocytes and eicosanoids level in patients with metabolic syndrome. Lipids in Health and Disease, 10, 82.
doi:10.1186/1476-511X-10-82

[5] Shalnova, S.A., Deev, A.D., Konstantinov, V.V. and Oganov, R.G. (2007) Hypertension and appraisal of the overall cardiovascular risk: Results of epidemiological monitoring of hypertension. Consillium Medicum, 11, 3135.

[6] Zvenigorodskaya, L.A., Homeric, S.G. and Egorova, E.G. (2008) Change the liver in insulin resistance. Hard Patient, 6, 71-74.

[7] Kuszakowski, M.S. (2002) Essential hypertension: Causes, mechanisms, clinical features, treatment. Pholiant, St. Petersburg, 416.

[8] Halperin, R.O., Sesso, H.D., Ma, J., Buring, J.E., Stampfer, M.J. and Gaziano, J.M. (2006) Dyslipidemia and the risk of incident hypertension in men. Hypertension, 47, 47-50.

[9] Psaty, B.M., Anderson, M., Kronmal, R.A., Tracy, R.P., Orchard, T., Fried, L.P., Lumley, T., Robbins, J., Burke, G., Newman, A.B. and Furberg, C.D. (2005) The association between lipid levels and the risks of incident myocardial infarction, stroke, and total mortality: The cardiovascular health study. Archives of Internal Medicine, 165, 24202427.

[10] Kovalenko, V.N., Mitchenko, E.I., Romanov, V.Y., Kulik, O., Logvinenko, A.A. and Gelmedova, M.F. (2008) Results of multicenter study to identify giperholeste rinemii-based analysis of regional centers of lipid. Ukrainian Journal of Cardiology, 8, 68-78.

[11] Sesso, H.D., Buring, J.E., Chown, M.J., Ridker, P.M. and Gaziano, J.M. (2005) A prospective study of plasma lipid levels and hypertension in women. Archives of Internal Medicine, 165, 2420-2427. doi:10.1001/archinte.165.20.2420

[12] O’Meara, J.G., Sharon, L.R., Armon, J.J., Brown, C.A., Boerwinkle, E. and Turner, S.T. (2004) Ethnic and sex differences in the prevalence, treatment, and control of dyslipidemia among hypertensive adults in the GENOA study. Archives of Internal Medicine, 164, 1313-1318. doi:10.1001/archinte.164.12.1313

[13] Arnett, D.K., Jacobs, D.R., Luepker, R.V., Blackburn H., Armstrong C. and Claas S.A. (2005) Twenty-year trends in serum cholesterol, hypercholesterinemia and cholesterol medication use. The Minnesota heart survey, 19801982 to 200-2002. Circulation, 112, 3884-3491. doi:10.1161/CIRCULATIONAHA.105.549857

[14] Goff, D.C., Bertoni, A.G., Kramer, H., Bonds, D., Blumenthal, R.S., Tsai, M.Y. and Psaty, B.M. (2006) Dyslipidemia prevalence, treatment, and control in the multiethnic study of atherosclerosis (MESA). Circulation, 113, 647-656. doi:10.1161/CIRCULATIONAHA.105.552737

[15] Anderson, K.M., Castelli, W.P. and Levy, D.B. (1987) Cholesterol and mortality: 30 years of follow-up from the Framingham study. Journal of the American Medical Association, 257, 2176-2180. doi:10.1001/jama.1987.03390160062027

[16] Liakishev, A.A. (2002) Correction of lipid disorders in patients with arterial hypertension. Russian Medical Journal, 10, 878-882.

[17] Kobalava, J.D. and Tolkachev, V.V. (2006) Hypercholes- 
terolemia and arterial hypertension. Heart, 4, 172-176.

[18] Martsevich, S.Y. (2005) Treatment of lipid disorders in patients with coronary heart disease. Treating Physician, 5, 42-45.

[19] Mitchenko, E.I. and Romanov, V.Y. (2007) The experience of the drug Cordon patients with arterial hypertension and dyslipidemia. Ukrainian Journal of Cardiology, 5, 73-77.

[20] Baigent, C., Keech, A., Kearney, P.M., Blackwell, L., Buck, G., Pollicino, C., Kirby, A., Sourjina, T., Peto, R., Collins, R. and Simes, R. (2005) Efficacy and safety of cholesterol-lowering treatment: Prospective meta-analysis of data from 90056 participant in 14 randomised trials of statins. Lancet, 366, 1267-1278. doi:10.1016/S0140-6736(05)67394-1

[21] Graham, D.J., Staffa, J.A., Shatin, D., Andrade, S.E., Schech, S.D., La Grenade, L., Gurwitz, J.H., Chan, K.A., Goodman, M.J. and Platt, R. (2004) Incidence of hospitalized rhabdomyolysis in patients treated with lipidlowering drugs. Journal of the American Medical Association, 292, 2585-2590. doi:10.1001/jama.292.21.2585

[22] Mancia, G., De Backer, G., Dominiczak, A., Cifkova, R., Fagard, R., Germano, G., Grassi, G., Heagerty, A.M., Kjeldsen, S.E., Laurent, S., Narkiewicz, K., Ruilope, L., Rynkiewicz, A., Schmieder, R.E., Struijker Boudier, H.A. and Zanchetti, A. (2007) Guidelines for the management of arterial hypertension: The task force for the management of arterial hypertension of the European society of hypertension (ESH) and European society of cardiology (ESC). Journal of Hypertension, 25, 1105-1187. doi:10.1097/HJH.0b013e3281fc975a

[23] Klimov, A.N. and Nikulicheva, N.G. (1999) Exchange of lipids and lipoproteins and its on-fracture: A guide for physicians. Peter Com, St Petersburg, 512

[24] Bligh, E.G. and Dyer, W.J. (1959) A rapid method of total lipid extraction and purification. Canadian Journal of Biochemistry and Physiology, 37, 911-917. doi:10.1139/059-099

[25] Carreau, J.P. and Duback, J.P. (1978) Adaptation of a macroscale method to the microscale for fatty acid methyl transesterification of biological lipid extract. Journal of Chromatography, 151, 384-390. doi:10.1016/S0021-9673(00)88356-9

[26] Stransky, K., Jursik, T., Vitek, A. and Skorepa, J. (1992) An improved method of characterizing fatty acids by equivalent chain length values. Journal of High Resolution Chromatography, 15, 730-740. doi:10.1002/jhrc. 1240151107

[27] Jamieson, G.R. (1975) GLC identification techniques for long-chain unsaturated fatty acids. Journal of Chromatographic Science, 13, 491-497.

[28] Medic, V.A. and Tokmachev, M.S. (2007) Mathematical statistics in medicine. Finances and Statistics, Moscow, 798.

[29] Potyomkin, V.V., Troitskaja, S.J. and Maksina, A.G. (2006) Metabolic indicators and struktura membranes erythrocytes at obesity and a metabolic syndrome at women. Russian Medical Journal, 1, 35-38.

[30] Novgorodtseva, T.P., Karaman, Y.K., Antoniuk, M.V. and Zhukova, N.V. (2009) The role of free and esterified fatty acids in pathogenesis of metabolic syndrome. Klinicheskaia Meditsina, 7, 33-37. 